\title{
The Influence of Cache Organization on E-Learning Environments
}

\author{
doi:10.3991/ijet.v4i2.652 \\ Ayman J. Nsour \\ Al_Isra Private University, Amman, Jordan
}

\begin{abstract}
This study examines the performance of an elearning environment in terms of average network traffic and upload/download rates under various cache memory organizations. In particular, we study the influence of three cache organizations, namely fully associative, direct, and set associative caches.
\end{abstract}

As a result of this work, we recommend the set associative cache memory organization with the Least Frequently Used (LFU) replacement policy, as this led to optimal performance in e-learning environments with the highest hit ratio and upload/download rates.

Index Terms-Synchronous E-Learning, Fully Associative Cache, Direct Mapping Cache, Set Associative Cache, Download And Upload Rates, Average Network Traffic, User Latency, Hit Ratio.

\section{INTRODUCTION}

Recent years have witnessed a revolutionized learning. Ever since the mid-nineties, educators gradually moved from conventional approaches and adopted an electronic learning (e-learning) approach.

Josh Bersin [3] classified e-learning applications into four categories: broadcast of new information, important knowledge transfer, developing new skills, and creating certified competencies. The fundamental strategies critical to developing efficient and effective e-learning environments were identified by Steiner [15]. Among the most important issues is performing a comprehensive, realistic analysis regarding the technical needs and specification of the e-learning project $[2,12,14]$.

Caching in e-learning environment is a vital performance solution that cannot be overlooked. Caching regularly accessed items on the e-learning environment is a significant technique to improve data availability and to decrease data access time. Because of limited cache size, cache replacement policies are used to find an appropriate subset of items for expulsion from the cache. The major problem being addressed is managing the various caching policies, strategies and organizations involved in an elearning environment in a way that leads to better performance [7]. The effects of different structures on the overall performance of the system are studied.

Our main focus is on e-learning at Al-Isra Private University, which is considered as a sample of higher education institues. We consider all four categories as well as a sub-area of the analysis of the cache memory organization under single-processing. We study how worthwhile it would be to vary cache organizations in e- learning environments. Moreover, we study the sideeffects forced by the adopted cache replacement policy.

\section{BACKGROUND AND PREVIOUS WORK}

Considerable work has been done on studying elearning environments. Albon and Tinidad at Curtin University of Technology [1,11] developed a Learner Mediated Approach (LMA) based on the nature of learning communities in which multiple approaches to learning reflect the learning process. They conducted an assessment of tasks, role of technology, and student processes in constructing knowledge, and concluded that LMA provides an approach in which the assessment drives the learning and the technology drives the model, creating a simultaneous and harmonious building of a learning community. Also, Serim [13] discussed professional development for building virtual communities and discussed the issues of moving from familiar models to constructs that would deliver unexplored environments for learning. Moreover, Chris Dede [5] studied the evolution of innovative learning devices including smart objects, information infrastructures, and shared synthetic environments, and addressed the importance of careful design of the interface among the devices, learners and instructors, in order to improve instructional outcomes. Last but not least, The effectiveness of web-based resources for teaching logic and discrete mathematics courses was examined by David Mudgett, Andrew Freed, and Frank Ritter at The Pennsylvania State University [10]. They observed improved student satisfaction (96\% of the students surveyed) in the course after developing a course web-site and using web-based resources.

The above litrarure highlights the need to develop an effective uploading and downloading traffic system to support developing e-learning applications. No dought, caching is one of the main parts in developing such traffic system, and thus, this paper studies caching in e-learning environments.

Caches differ in many aspects, the major distinguishing characteristics are [4]:

- Memory Organization: The internal arrangement of the cache is a crucial factor that reflects the mapping of Web objects into the cache. There are various arrangements:

1) Fully Associative (FA)Cache

2) Set Associative (SA) Cache

3) Direct Mapping (DM) Cache 
- Replacement Policy: Real caches have finite sizes, and thus a request for a non-cached document may cause the removal of one or more cached documents (unless direct mapping is implemented). Some of the important cache replacement policies are:

1) Least Recently Used (LRU).

2) First In First Out (FIFO).

3) Least Frequently Used (LFU).

4) LRUMIN.

One LRU extension is proposed by devising a scheme called Pyramidal Selection Scheme, or PSS. The PSS is a variant of its theoretical ancestor Size-Adjusted LRU or SLRU also developed by the same authors.

The SLRU requires the sum of dynamic frequencies for outgoing objects to be as small as possible, i.e. replace the objects with the best cost-to-size ratio. Since this policy is difficult to implement in practice, because of the difficulty in comparing the product of the size and the time since last access for every object in the cache, the authors devised a more practical variant, the Pyramidal Selection Scheme, or PSS. The PSS classifies objects in the cache in a pyramidal fashion depending upon their size. Whenever a decision is to be made about which cache object must be replaced, the product is compared for only the least recently used object in each group. They concluded that the PSS is a practical and viable caching algorithm, which is applicable to proxy and client caches.

Other studies $[6,8,9,16]$ have shown that there is an opportunity to improve user response time from cache by improving the cache consistency mechanism and that when a validation is returned form cache directly; it is returned approximately an order of magnitude faster than an object that requires a consistency check.

\section{OBJECtIVE AND PROPOSED Model}

We aim at studying the influence of cache organization on e-learning environments in terms of average network traffic, upload and download rates.

\section{A. E-learning Environment Argument Values}

Our study took place at Al-Isra Private University labs. The e-learning environment is synchronous and uses both audio and video conferencing, in addition to chat rooms. In order to achieve our aim, certain system arguments were taken into consideration and assigned values which are shown in Table 1.

TABLE I.

ENVIRONMENT ARGUMENTS

\begin{tabular}{|c|c|}
\hline Argument & Value \\
\hline Network Bandwidth & $10 \mathrm{Mb}$ \\
\hline Printer Job Size & $50 \mathrm{~Kb}$ \\
\hline Voice Packet Size & $25 \mathrm{~Kb}$ \\
\hline Text Packet Size & $8 \mathrm{~Kb}$ \\
\hline Process Queue Size & 60 \\
\hline Image Size & $17 \mathrm{~Kb}$ \\
\hline Image Upload Rate & $5 \mathrm{Kbps}$ \\
\hline
\end{tabular}

These values are set for each LAN, whereas each lab represents a stand-alone LAN. The assumptions in our model can be summarized as follows:

- The instructor may not be physically available in the lab.

- Each lab is connected to one printer.

- Every student (client) may use a web cam and a microphone.

- All PCs (clients) operate under a single processing capability.

\section{B. Caching Argument Values}

The assumptions and strategies used in our model can be summarized as follows:

- Maximum cache size is $512 \mathrm{~Kb}$.

- Cache word size is 4 bytes.

- Main memory size is $64 \mathrm{Mb}$.

- The size of Main memory word is 4 bytes.

- A time-out occurs at a user-latency greater than 45 seconds. Time-out is defined as the stage when no more delay is accepted and the request has to be reissued.

- For the cache memory organization and mapping strategy, each of FA, SA (of size 4 words), and DM was considered:

- The cache fetching policy adopted is on-demand.

- Several policies have been proposed in the literature for cache replacement, but not all have been implemented in this study. In all replacement policies, it is assumed that all removals from the cache are done only upon need and not based on any other time-dependent criterion. The following were taken into consideration:
o First In First Out (FIFO)
o Least Recently Used (LRU)
o Least Frequently Used (LFU)

\section{Workloads}

Workloads have been collected at 7 different labs, each running for 1 hour and having 20 PCs. The reason behind this classification lies in following the standards followed at Al-Isra Private University in offering such lab duration for most courses. Workloads have been collected at 10 different sessions to give a more representative average case.

On the other hand, artificial workloads were also used. The reason behind using artificial workloads is to generate representative access patterns that are possible and significant but are not easily found in real-systems' traces.

\section{Our Simulator}

A simulator was built in order to study the influence of these capabilities on the environment and workloads have been fed to the simulator. The simulator was run under the same environmental factors present in the real singleprocessing environment.

The simulator was built by developing a process structure that identifies all attributes needed for a network process that covers all previously stated model assumptions. Each operation category (uploading for example) has its own separate queue that is limited, not by 
the number of processes in the queue, but by the configuration assigned for environment variables designed for that queue. Threading was used in order to allow for multiple clients to operate at the same time.

On the other hand, both the cache and main memories were implemented as an array of structures. The structure represents the memory word, and arrays were used since both memories have a fixed-size nature.

The processor was simulated to generate memory requests on a random basis. Whenever a request is made, a record is kept on the number or hits and misses for hit ratio calculation purposes.

We have conducted two experiments; the first of which aimed at evaluating the influence of various cache memory organizations. The second experiment aimed at studying the effects a replacement policy forces.

\section{RESULTS AND ANALYSIS}

We now present the results obtained from our study. All experiments operated on both real-system and artificial workloads. We classify the results as:

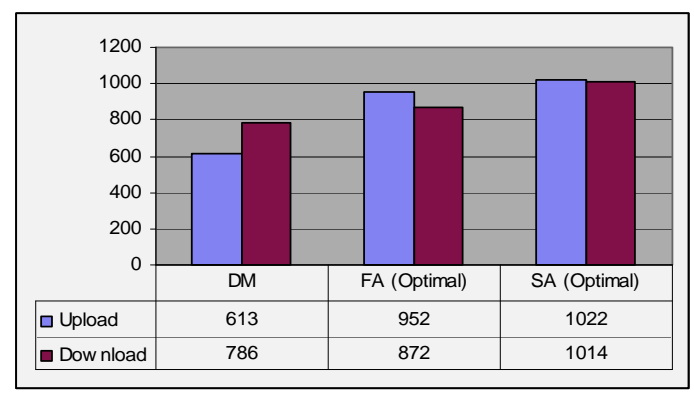

Figure 1. Average Upload/Download Rates for Various Cache Organizations

- The influence of Cache Memory Organization on Average Upload/Download Rates: As shown in Figure 1, there are noticeable differences between various cache memory organizations. It should be noted that the figure shows the optimal case in which FA and SA caches performed, i.e. it was based on the results obtained from replacement policies.

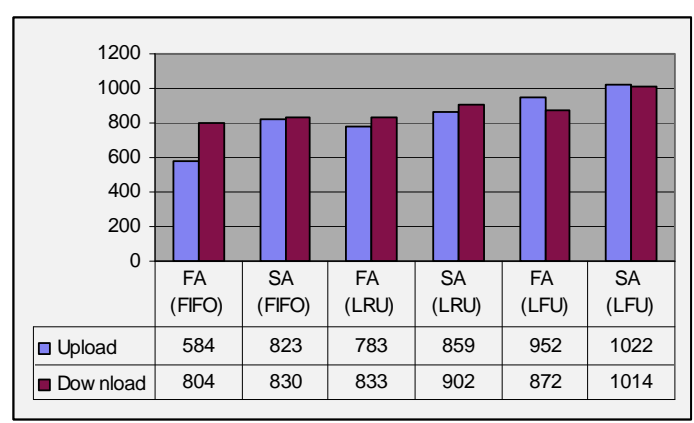

Figure 2. Average Upload/Download Rates for Various Replacement Policies

- The influence of Cache Replacement Policies on Average Upload/Download Rates: Figure 2 demonstrates the influence of cache replacement polices. DM is not shown as the organization does not use a replacement policy. It follows logically that FIFO gave the worst results. The difference between LFU and LRU were sometimes marginal, though LFU gave better results on an average basis.

\section{CONCLUSION}

Table 2 summarizes the results of our work. Having conducted the previously stated experiments and analyzed the obtained results, we conclude that set associative caches are most suitable for e-learning environments in, at least, Al-Isra Private University. Of course the LAN arguments have a big role on selection of the type of the cash. Moreover, the frequency in which requests are issued is the best placement policy in terms of upload/download rates.

TABLE II.

SUMMARY OF RESUlTS AVERAGE UPLOAD/DOWNLOAD RATES FOR VARIOUS REPLACEMENT POLICIES

\begin{tabular}{|c|c|c|}
\hline Cache/Criterion & $\begin{array}{c}\text { Avg. Upload } \\
\text { Speed }\end{array}$ & $\begin{array}{c}\text { Avg. Download } \\
\text { Speed }\end{array}$ \\
\hline FA (FIFO) & $584 \mathrm{Kbps}$ & $804 \mathrm{Kbps}$ \\
\hline SA (FIFO) & $823 \mathrm{Kbps}$ & $830 \mathrm{Kbps}$ \\
\hline FA (LRU) & $783 \mathrm{Kbps}$ & $833 \mathrm{Kbps}$ \\
\hline SA (LRU) & $859 \mathrm{Kbps}$ & $902 \mathrm{Kbps}$ \\
\hline FA (LFU) & $952 \mathrm{Kbps}$ & $872 \mathrm{Kbps}$ \\
\hline SA (LFU) & $1022 \mathrm{Kbps}$ & $1014 \mathrm{Kbps}$ \\
\hline DM & $613 \mathrm{Kbps}$ & $786 \mathrm{Kbps}$ \\
\hline
\end{tabular}

\section{REFERENCES}

[1] Albon, R. \& Tinidad, S. (2002). Building Learning Communities Through Technology, retrieved July 5, 2003 ; URL: www.library.cqu.edu.au/conference/ papers/Albon Trinidad.pdf

[2] Beilawski, L. \& Metcalf, D. (2002). Blended E-learning, Human Resource Development Project.

[3] Bersin, J. (2003). The Four Categories of E-Learning, retrieved July 30, 2003 from http://www.bersin.com/tips techniques/breeze2.htm.

[4] Cheriton, D. \& Duda, K. (2000). A Caching Model of Operating System Kernel Functionality; URL http://www-dsg.stanford.edu/ papers/cachekernel/main.html

[5] Dede, Ch. (1996). The Evolution of Learning Devices: Smart Objects, Information Infrastructures, and Shared Synthetic Environments, retrieved July 5, 2003 from http://www.ed.gov/ Technology/Futures/dede.html

[6] Dilley, J., (1999). The Effect of Consistency on Cache Response Time. $\quad$ http://www.hpl.hp.com/techreports/1999/HPL-1999107.html

[7] Horton, W. (2001). Evaluating E-Learning, American Society for Training and Development.

[8] Intel of Canada. (2003). Hyper-Threading Technology: TurboCharging PCs to Hit a New High in Performance, retrieved July 5, 2003 from http://www.intel.com/ca/pressroom/kits/p4/cpk/HTT/ HTbackgrounderCANADA.pdf

[9] Marr, D., Binns, F., Hill, D., Hinton, G., Koufaty, D., Miller, J., and Upton, M. (2002). Hyper-Threading Technology Architecture and Microarchitecture. Intel Technology Journal, 6 (1); http://www.intel.com/technology/itj/2002/volume06issue01/art01h yper/vol6iss1art0l.pdf

[10] Mudgett, D., Freed, A. \& Ritter, F. (2002). Web-Based Resources for Teaching Discrete Mathematics to Students of Information Sciences and Technology. Learning Technology, 4 (3); http://ttf.ieee.org/learn tech/issues/july2002/.

[11] Paynter, J. (2002). A comparison of computer mediated training tools. Learning Technology, 4 (3); http://ttf.ieee.org/learn tech/issues/july2002/ 
[12] Ryan, B. \& Walmsley, S. (2003). Implementing metadata collection. Learning Technology, 5 (1); http://lttf.ieee.org/ learntech/issues/january2003/

[13] Serim, F. (1996). Building Virtual Communities for Professional Development, retrieved Nov 8, 2003 from http://www.ed.gov/ Technology/Futures/serim.html

[14] Simpson, W. (2002). Online learning: a project to develop an innovative approach to control. Learning Technology, 4 (3); http://ttf.ieee.org/learn tech/issues/juIy2002/

[15] Steiner, M. (2003). Critical strategies for a successful e-learning project, retrieved July 30, 2003 from http://www.macromedia. com/devnetleducation/articles/awplanning.html.
[16] Wilkinson, B., (1996). Computer Architecture Design and Performance, $2^{\text {nd }}$ edition. Prentice Hall, Europe.

\section{AUTHOR}

Ayman J. Nsour is with Al_Isra Private University/Department of Computer Science, Amman, Jordan.

Manuscript received 3 September 2009. Published as submitted by the author. 